\title{
No vessel wall abnormalities in a human foetus with a NOTCH3 mutation
}

\author{
Saskia A. J. Lesnik Oberstein • Marion L. C. Maat-Schieman • Elles M. J. Boon • \\ Joost Haan · Martijn H. Breuning · Sjoerd G. van Duinen
}

Received: 18 October 2007 / Revised: 20 December 2007 / Accepted: 20 December 2007 / Published online: 12 January 2008

(C) The Author(s) 2008

Cerebral autosomal dominant arteriopathy with subcortical infarcts and leukoencephalopathy (CADASIL) is hereditary and caused by mutations in the NOTCH3 gene [1]. Typical arterial wall changes in CADASIL are destruction of vascular smooth muscle cells (VSMC) and accumulation of granular osmiophilic material (GOM) and NOTCH3 protein ectodomain at the VSMC surface [2]. These abnormalities are already present in the (skin) vasculature of young adult presymptomatic mutation carriers [3]. However, it is unknown when arterial and VSMC abnormalities in CADASIL initiate. The expression of NOTCH3 in VSMC in the very early stages of development has recently been reported by Ichinohe et al. [4]. The purpose of this study was to investigate whether vessel wall abnormalities characteristic for CADASIL are already detectable in a foetus

\footnotetext{
S. A. J. Lesnik Oberstein $(\bowtie) \cdot$ E. M. J. Boon · M. H. Breuning Department of Clinical Genetics,

Center for Human and Clinical Genetics,

Leiden University Medical Center, PO BOX 9600,

2300 RC Leiden, The Netherlands

e-mail: Lesnik@LUMC.nl

M. L. C. Maat-Schieman · J. Haan · S. G. van Duinen

Department of Neurology,

Leiden University Medical Center,

Leiden, The Netherlands

M. L. C. Maat-Schieman · S. G. van Duinen

Department of Pathology,

Leiden University Medical Center,

Leiden, The Netherlands

J. Haan

Department of Neurology,

Rijnland Hospital, Leiderdorp, The Netherlands
}

with a NOTCH3 mutation. We studied the vasculature of an aborted 14-week-old foetus affected by a NOTCH3 mutation, and a control foetus of approximately the same gestational age, by means of histology, electron microscopy and immunohistochemistry using a NOTCH3 monoclonal antibody (provided by Anne Joutel, Paris, France).

The foetal tissue was acquired through a termination of pregnancy (TOP), after prenatal diagnosis via DNA-testing in the chorionic villi. Prenatal testing was performed on request from the parents, as one of them was a carrier of a NOTCH3 mutation, with a positive family history for CADASIL, and they did not wish to pass on the NOTCH3 mutation to their child. The foetus was found to be heterozygous for the same common pathogenic NOTCH3 mutation as its parent (p.Arg153Cys in exon 4). Oral and written consent was given by the parents to use the foetal tissue for CADASIL research purposes and approval was obtained from the medical ethics committee of the Leiden University Medical Center. The control foetus was obtained after an elective TOP, according to the procedures of the medical ethical committee approved protocol of donating foetal material for scientific research after TOP. Autolysis time was no more than $1 \mathrm{~h}$. Tissue specimens were collected from the fragmented tissue masses. From the CADASIL foetus these included: brain, intestine, heart, liver, vertebra and surrounding tissues, upper and lower extremity, placenta and umbilical cord, and from the control foetus: brain, lung, vertebra and surrounding tissues, upper and lower extremity and placenta.

The tissues were formalin fixed, embedded in paraffin and stained with hematoxylin and eosin (H\&E) and the Verhoeff van Gieson (VvG) stain.

Immunostaining with monoclonal antibodies against alpha smooth muscle actin (alpha-SMA; Progen, Heidelberg) and NOTCH3 1E4 was performed on all tissue specimens of both the CADASIL and control foetus according to 
Fig. 1 Small cerebral vessel (a-c) and small subcutaneous vessel (d) of the foetus with a NOTCH3 mutation. Light microscopy shows a normal vessel wall in the H\&E stain (a). Anti-alpha SMA demonstrates the presence of a normal smooth muscle layer (b) and anti-NOTCH3 staining is negative (c). Electron microscopy $(\times 10,000)$ shows normal structured layers of the vessel, including the endothelial cells and pericyte (right) and some basement membrane material in between, without the presence of GOM or signs of degeneration $(\mathbf{d})$

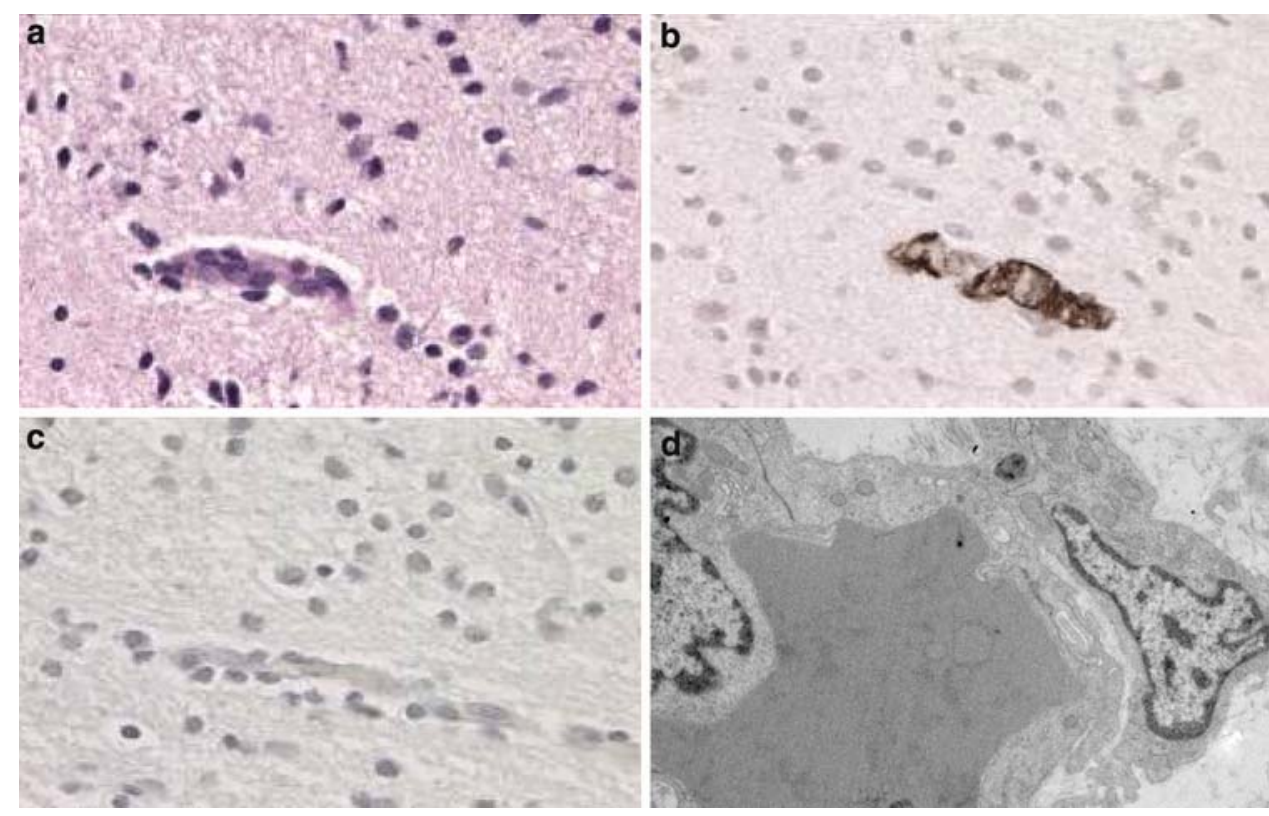

previously described techniques [3]. Brain tissue of a genetically proven CADASIL patient served as a positive control for the NOTCH3 staining. For ultrastructural examination, tissues of the CADASIL foetus (brain, heart, extremity (skin and muscle) and placenta) and the control foetus (brain, lung, extremity (skin and muscle) and placenta) were fixed in $1.5 \%$ glutaraldehyde and $1 \%$ paraformaldehyde in cacodylate buffer, post-fixed in $1 \%$ osmium tetroxide and processed for Spurr embedding. Subsequently, sections were cut, contrasted with uranyl acetate and lead citrate and examined in a JEOL JEM-1011 electron microscope. The examination focussed in particular on the presence of GOM or signs of (early) VSMC degeneration in the blood vessels.

The material was well fixed without signs of autolysis. Neither the control nor the CADASIL foetal tissue showed abnormalities on $\mathrm{H} \& \mathrm{E}$ and $\mathrm{VvG}$ staining, including the vessels in the available brain tissue and peripheral tissues. There were no thickened vessels or abnormal deposits in the vessel walls (see Fig. 1a). Immunostaining did not reveal positive NOTCH3 staining of vessels or other structures in any of the tissues that were examined. The positive CADASIL control tissue consistently showed the typical granular staining pattern of affected vessel walls. All larger vessels showed a regular positivity for alphaSMA (see Fig. 1b, c). CADASIL foetal vessels did not contain GOM. The morphology of the VSMC was not different from that of the control foetus. No changes were seen in other vascular wall structures, including the endothelium (see Fig. 1d). The finding of normal arterioles in an affected foetus suggests that arterial wall and VSMC abnormalities in
CADASIL initiate in the course of the first two decades of life. This is relevant for future studies aimed at unravelling the pathophysiology of CADASIL and also implies that, theoretically, early intervention, for example in the form of genetic modulation therapy, could prevent or delay the disease process.

Acknowledgments The authors thank Mrs. Ingrid M. HegemanKleinn for technical assistance and Frans J. C. M. Klumper.

Open Access This article is distributed under the terms of the Creative Commons Attribution Noncommercial License which permits any noncommercial use, distribution, and reproduction in any medium, provided the original author(s) and source are credited.

\section{References}

1. Joutel A, Vahedi K, Corpechot C, Troesch A, Chabriat H, Vayssière C, Cruaud C, Maciazek J, Weissenbach J, Bousser M-G, Bach MA, Tournier-Lasserve E (1997) Strong clustering and stereotyped nature of Notch 3 mutations in CADASIL patients. Lancet 350:1511-1515

2. Joutel A, Andreux F, Gaulis S, Domenga V, Cecillon M, Battail N, Piga N, Chapon F, Godfrain C, Tournier-Lasserve E (2000) The ectodomain of the Notch3 receptor accumulates within the cerebrovasculature of CADASIL patients. J Clin Invest 105:597605

3. Lesnik Oberstein SA, van Duinen SG, van den Boom R, MaatSchieman ML, van Buchem MA, van Houwelingen HC, HegemanKleinn IM, Ferrari MD, Breuning MH, Haan J (2003) Evaluation of diagnostic NOTCH3 immunostaining in CADASIL. Acta Neuropathol (Berl) 106:107-111

4. Ichinohe A, Takahashi K, Tabira T, Takashima S (2005) Early and late development of Notch3 in human brains. Neuroembryology 3:13-18 